\title{
Analysis of the Lingula Shapes in Macerated Mandibles of Brazilian Individuals
}

\author{
Análisis de la Forma de la Língula en Mandíbulas Maceradas de Individuos Brasileños
}

\author{
Nilton Alves* \& Naira Figueiredo Deana**
}

ALVES, N. \& DEANA, N. F. Analysis of the lingula shapes in macerated mandibles of Brazilian individuals. Int. J. Morphol., 34(1):4248, 2016.

SUMMARY: The lingula of the mandible is a bone projection that limits medially the mandibular foramen, which is the region where the inferior alveolar neurovascular bundle penetrates. The lingula is an important anatomical landmark used in maxillofacial surgeries and to block the inferior alveolar nerve. The aim of this study was to analyze the different types of lingula found in mandibles of Brazilian individuals, considering aspects such as gender and race. One hundred thirty-two macerated mandibles of Brazilian adult individuals of both sexes, black and white skin colors, were used. The lingula was classified into four types: triangular, truncated, nodular and assimilated. The data were analyzed using Chi-square test and Fisher's exact test. The truncated shape was the most commonly found (49\%), followed by nodular (26.5\%) and triangular $(23.3 \%)$ shapes. The assimilated shape was significantly less prevalent with $1.2 \%$. Each type of the lingula was more often bilateral rather than unilateral. Considering skin color we observed that the truncated shape was more prevalent in black individuals than in white individuals and the nodular shape was more prevalent in white individuals than in black individuals. There was no case of assimilated shape in black individuals. Considering gender we observed that the truncated shape was more prevalent in females than in males and the triangular shape was more prevalent in males than in females. The lingula shape showed no side preference. Our findings facilitate the planning of oral and maxillofacial surgical procedures that involve the lingula and/or the inferior alveolar neurovascular bundle, avoiding operative complications.

KEY WORDS: Anatomy; Lingula; Mandible; Inferior alveolar nerve.

\section{INTRODUCTION}

The lingula of the mandible is a bone projection that limits medially the mandibular foramen, which is the region where the inferior alveolar neurovascular bundle penetrates (Alves \& Cândido, 2012). The lingula is a structure that varies in size and shape, which may be truncated, triangular, nodular or assimilated (Tuli et al., 2000).

The lingula is an important anatomical landmark used in maxillofacial surgeries, such as in sagittal split ramus osteotomy technique (Sekerci \& Sisman, 2014). Some authors consider this anatomical structure as an ideal reference point for the horizontal osteotomy (Salgado et al., 2012), which must be performed just above the lingula (Dal Pont, 1961) where some complications, such as injury to the inferior alveolar nerve, can occur determining a neurosensory disturbance (Yoshida et al., 1989). Furthermore, the morphology of the lingula is important to the maxillofacial surgeons for determining the distance to mandibular foramen entrance (Sekerci \& Sisman). Others authors affirm that the variability of the lingula and the mandibular foramen may be responsible for an occasional failure to block the inferior alveolar nerve (Nicholson, 1985; Keros et al., 2001). According Alves \& Cândido furthermore, other anatomical conditions may determine failure of inferior alveolar nerve block, as in the case of patients who have a very broad sphenomandibular ligament since this ligament is inserted into the lingula, so when it presenting these features may act as a waterproofing agent, preventing the action of anesthetic.

The aim of this study was to analyze the different shapes of lingula found in macerated mandibles of Brazilian individuals, considering aspects such as sex and race. Furthermore, we performed a literature review to determine the types of lingula found within different populations.

\footnotetext{
* CIMA Research Group, Faculty of Dentistry, Universidad of La Frontera, Temuco, Chile.

** Private Physical Therapist, Temuco, Chile.
} 


\section{MATERIAL AND METHOD}

One hundred thirty-two macerated mandibles of Brazilian adult individuals of both sexes, black and white skin colors were used in the present study. Were excluded from this study edentulous mandibles and/or those that did not contain information on sex and race. We included only wholly or partially dentate hemimandibles that had at least one molar in the hemiarcade being studied.

Regarding its shape, the lingula was classified into four types (Fig. 1), according Tuli et al.: triangular, when a broad base presented and a pointed apex; truncated, when quadrangular apex presented; nodular, when it almost completely incorporated into the mandibular ramus, except by its apex; assimilated, when it fully incorporated into the mandibular ramus. We also analyzed whether the shape of the lingula was the same bilaterally or not.

The data obtained were tabulated and analyzed using Chi-square test and Fisher's exact test, as applicable. Was considered statistically significant $\mathrm{p} \leq 0.05$.
Furthermore, studies published in the medical literature were analyzed, after review in Pub-Med/ MEDLINE, SCOPUS, ISI Web of Knowledge, LILACS and SciELO. Articles were searched using the keywords "lingula", "shape", "dry mandible". Original articles, longitudinal prospective studies and retrospective studies were included, which were published between 2000 and 2014. We excluded articles without abstract available, case reports, systematic reviews, researches performed in samples of children and articles in different language than English, Portuguese and Spanish.

\section{RESULTS}

A total of 17 non-overlapping articles (9 in Pub-Med/ MEDLINE, 4 in SCOPUS, 3 in ISI Web of Knowledge, 1 in LILACS and 0 in Scielo) were found and a total of 10 articles were selected for inclusion in this study (Table I).

A total of 253 hemimandibles (96 black males, 69 white males, 62 black females and 26 white females) were

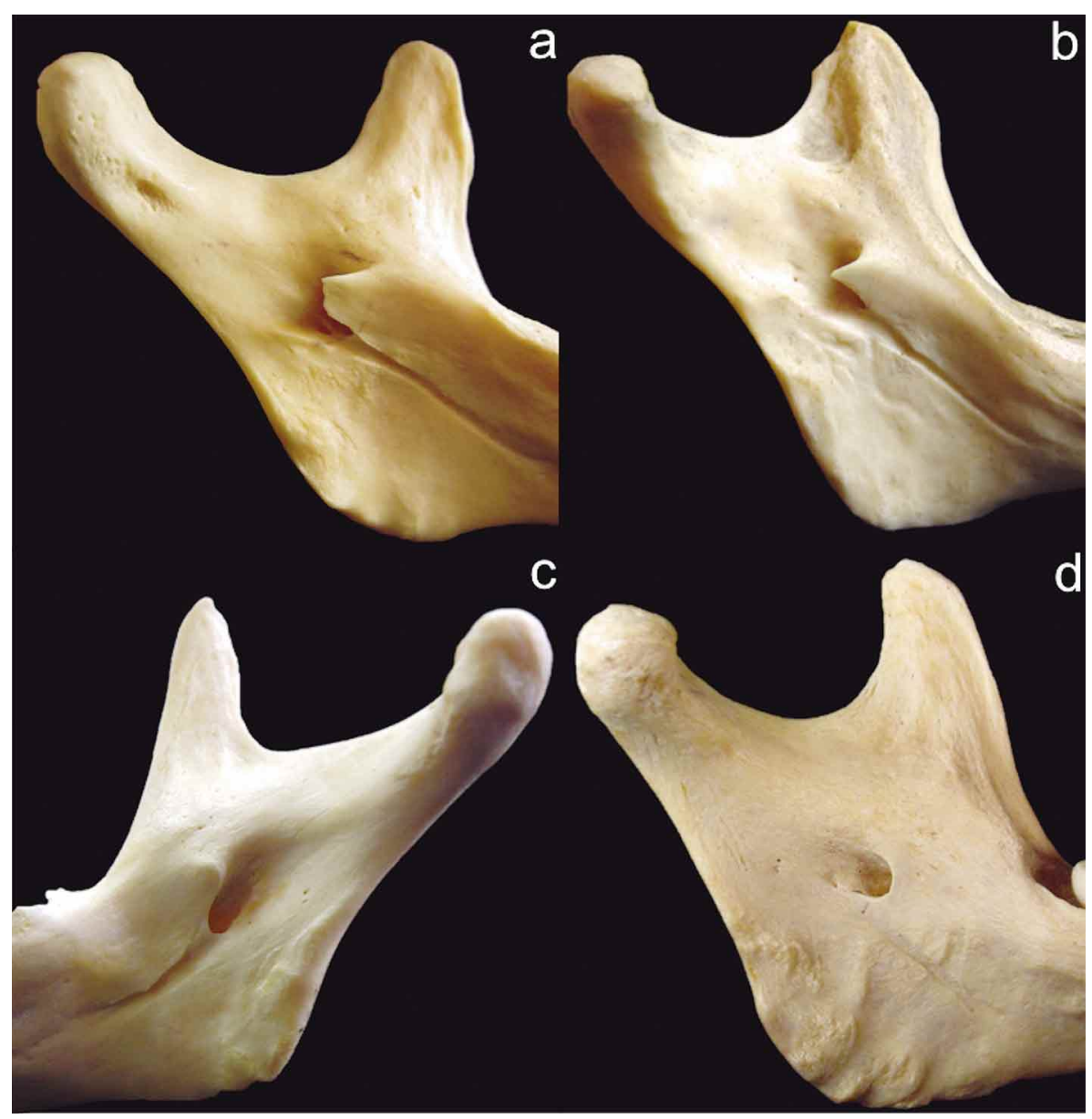

Fig. 1. Morphological classification of the lingula. A. Truncated. Shows quadrangular apex. B. Triangular. Shows a broad base and a pointed apex. C. Nodular. Almost completely incorporated into the mandibular ramus. D Assimilated. Fully incorporated into the mandibular ramus. 
Table I. Percentage of lingula shapes reported in the literature and in the present study.

\begin{tabular}{|c|c|c|c|c|c|c|c|}
\hline \multirow{2}{*}{ Authors } & \multirow{2}{*}{ Year } & \multirow{2}{*}{$\mathrm{n}$ of sides } & \multirow{2}{*}{ Population } & \multicolumn{4}{|c|}{ Shape } \\
\hline & & & & Truncated & Triangular & Nodular & Assimilated \\
\hline Tuli et al. & 2000 & 330 & Indian & $15.8 \%$ & $68.5 \%$ & $10.9 \%$ & $4.8 \%$ \\
\hline Kositbowornchai et al. & 2007 & 144 & Thai & $47.2 \%$ & $16.7 \%$ & $22.9 \%$ & $13.3 \%$ \\
\hline Jansisyanont et al. & 2009 & 146 & Thai & $46.2 \%$ & $29.9 \%$ & $19.6 \%$ & $4.3 \%$ \\
\hline Lopes et al. & 2010 & 160 & Brazilian & $36.3 \%$ & $41.3 \%$ & $10.5 \%$ & $11.9 \%$ \\
\hline Murlimanju et al. & 2012 & 134 & South Indian & $27.6 \%$ & $29.9 \%$ & $29.9 \%$ & $12.6 \%$ \\
\hline Nirmale etal. & 2012 & 168 & --- & $10.7 \%$ & $47.6 \%$ & $28.0 \%$ & $13.7 \%$ \\
\hline Shenoy et al. & 2012 & 100 & --- & $29.0 \%$ & $23.0 \%$ & $39.0 \%$ & $9.0 \%$ \\
\hline Lavanya Varma \& Sammer & 2013 & 366 & South Indian & $29.0 \%$ & $13.0 \%$ & $42.0 \%$ & $6.0 \%$ \\
\hline Tapas & 2013 & 100 & --- & $36.0 \%$ & $42.0 \%$ & $10.0 \%$ & $12.0 \%$ \\
\hline Sekerci \& Sisman & 2014 & 824 & Turkish & $32.0 \%$ & $14.1 \%$ & $51.2 \%$ & $2.7 \%$ \\
\hline Present study & 2015 & 253 & Brazilian & $49.0 \%$ & $23.3 \%$ & $26.5 \%$ & $1.2 \%$ \\
\hline
\end{tabular}

(-) not informed.

analyzed in this study. The truncated shape was the most commonly found (49\%), followed by nodular (26.5\%) and triangular $(23.3 \%)$ shapes. The assimilated shape was significantly less prevalent with only $1.2 \%$. The Table I shows the percentage of each type of lingula found in the literature and in this study.

Analysis by sex. Correlating the shape of the lingula with sex, we observed that the truncated shape was the most frequently found in both sexes, being more prevalent in females than in males $(\mathrm{p}=0.0006)$. The assimilated shape was the least frequent in both sexes. The triangular shape were more prevalent in males than in females $(\mathrm{p}=0.007)$. The nodular shape showed no statistically significant differences between the sexes. The Table II shows the percentage of each type of lingula according to sex.
Comparing sex, considering skin color we found that the triangular shape was more prevalent in black males than in black females $(p=0.03)$. The truncated shape was more prevalent in white females than in white males $(\mathrm{p}=0.0009)$ and the nodular shape was more prevalent in white males than in white females (Table III). Table IV shows the percentage of each type of lingula according to sex, found in the literature.

Analysis by race. We observed that between black and white individuals there was statistically significant difference in truncated shape $(\mathrm{p}=0.05)$, which was more frequent in black individuals; nodular shape $(\mathrm{p}=0.05)$ and assimilated shape $(\mathrm{p}=0.05)$ which were more frequent in white individuals. There was no case of assimilated shape in black individuals (Table II).
Table II. Percentage of lingula shapes for males, females, black and white individuals.

\begin{tabular}{lcccc}
\hline & Truncated & Triangular & Nodular & Assimilated \\
\cline { 2 - 5 } Males & $40.6 \%^{*}$ & $28.5 \%^{*}$ & $29.7 \%$ & $1.2 \%$ \\
Females & $64.8 \%^{*}$ & $13.6 \%^{*}$ & $20.3 \%$ & $1.3 \%$ \\
Black individuals & $53.8 \%^{\dagger}$ & $24.0 \%$ & $22.2 \%^{\dagger}$ & $0 \%^{\dagger}$ \\
White individuals & $41.0 \%^{\dagger}$ & $22.1 \%$ & $33.8 \%^{\dagger}$ & $3.1 \%^{\dagger}$ \\
\hline
\end{tabular}

*statistically significant difference between sex; $\uparrow$ statistically significant difference between race.

Table III. Percentage of lingula shapes for black males, white males, black females and white females.

\begin{tabular}{lcccc}
\hline & Truncated & Triangular & Nodular & Assimilated \\
\cline { 2 - 5 } Black Males & $47.9 \%^{\dagger}$ & $30.2 \%^{*}$ & $21.9 \%^{\dagger}$ & $0 \%$ \\
White Males & $30.5 \% \%^{* *}$ & $26 \%$ & $40.6 \% \%^{*}$ & $2.9 \%$ \\
Black Females & $62.9 \%$ & $14.5 \%^{*}$ & $22.6 \%$ & $0 \%$ \\
White Females & $69.2 \%^{*}$ & $11.5 \%$ & $15.5 \% *$ & $3.8 \%$ \\
\hline
\end{tabular}

*statistically significant difference between sex; † $\uparrow$ statistically significant difference between race.
We found that the truncated shape was more prevalent in black males than in white males $(\mathrm{p}=0.02)$ and the nodular shape was more prevalent in white males than in black males $(p=0.01)$. Between black females and white females there was no statistically significant difference for any shape of lingula (Table III).

Analysis by side. This study found no preference for side related to the shape of lingula.

Analysis by simmetry between sides. We observed that the symmetry of the lingula was more common than the asymmetry. The symmetry of the truncated shape was the most frequent $(52.7 \%)$, followed by the nodular shape $(25.8 \%)$ and then by the trian- 


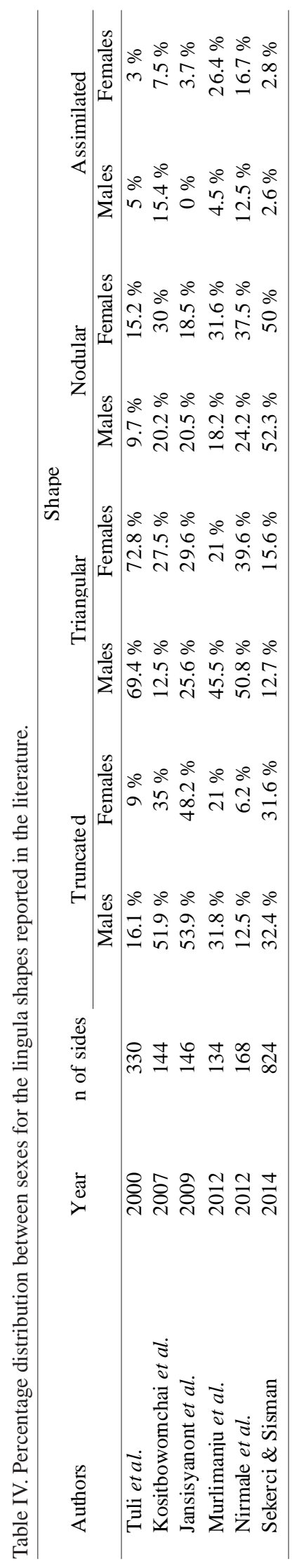

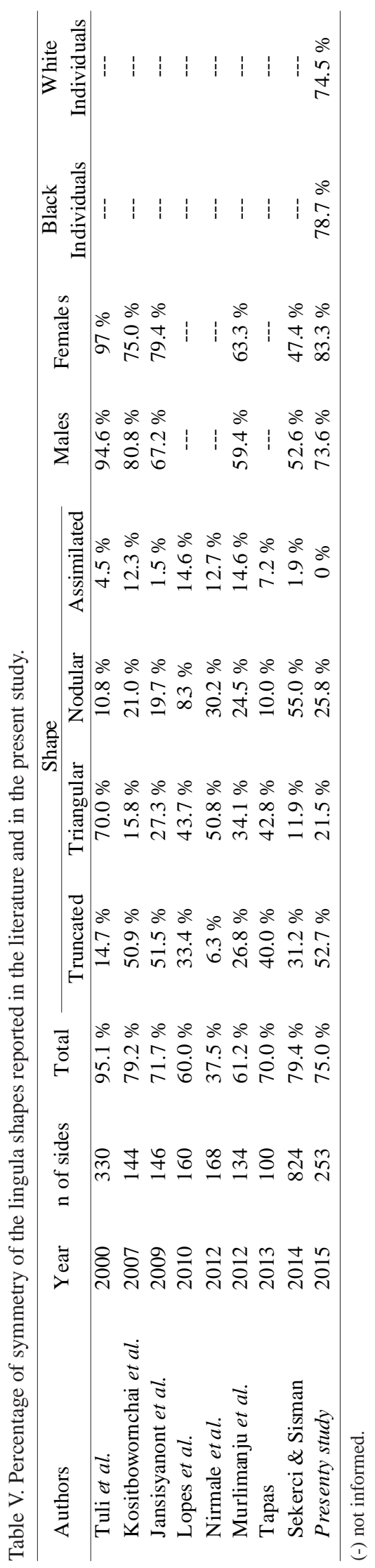

gular shape $(21.5 \%)$ (Table V). The most common type of asymmetry in males, females and black individuals was "truncated $\mathrm{x}$ triangular", in white individuals was "truncated $\mathrm{x}$ nodular". Other types of asymmetries were found in a lower percentage. The assimilated shape presented no bilateral case. Just the bilateral truncated shape was more prevalent in females than in males $(\mathrm{p}=0.001)$. There were no statistically significant differences between races (Table VI). The Table V shows the percentage of simmetry of the lingula shapes, found in the literature and in this study.

\section{DISCUSSION}

The importance of the morphological study of the lingual is unquestionable, since this anatomical structure is an important anatomical landmark used in maxillofacial surgeries. We agree with Jansisyanont et al. (2009) when they affirm that the shape of the lingula is important for surgeons to identify its location more easily during ramus surgery. According to Alves \& Deana (2015) there is a relationship between the shape of the lingula and its location in the ramus of mandible. These authors claim that in general, lingulas with triangular shape are located slightly more posterior than lingulas with nodular shape. They emphasize that is very important to consider these data when performing surgical procedures involving ramus of mandible, since the lingula marks the entrance of the inferior alveolar neurovascular bundle.

The shape of the lingula is variable in different populations (Nicholson; Tuli et al.; Kositbowornchai et al., 2007). Despite all this, we did not find in the literature, any study correlating the shape of the lingula with race. In this study, in which macerated mandibles of Brazilian adult individuals of both sexes, black and white skin colors were used, the truncated shape was the most prevalent, a fact also reported to Thai individuals (Kositbowornchai et al.; Jansisyanont et al.), however, for Nirmale et al. (2012) was the least prevalent shape, reaching $10.7 \%$. The triangular shape was the most prevalent according Nirmale et al., Tapas (2013) and Lopes et al. (2010) who reported 
Table VI. Percentage of the lingula shape (right and left sides) found for males, females, black and white individuals.

\begin{tabular}{lcccc}
\hline Right x Left & Males & Females & Black Individuals & White Individuals \\
\hline Truncated x Truncated & $30.0 \%$ & $59.5 \%$ & $44.0 \%$ & $34.0 \%$ \\
Truncated x Triangular & $6.2 \%$ & $7.1 \%$ & $8 \%$ & $4.2 \%$ \\
Truncated x Nodular & $5.0 \%$ & $2.4 \%$ & $2.7 \%$ & $6.4 \%$ \\
Truncated x Assimilated & $0 \%$ & $0 \%$ & $0 \%$ & $0 \%$ \\
Triangular x Truncated & $5.0 \%$ & $2.4 \%$ & $5.3 \%$ & $2.1 \%$ \\
Triangular x Triangular & $20.0 \%$ & $9.5 \%$ & $16.0 \%$ & $17.0 \%$ \\
Triangular x Nodular & $1.3 \%$ & $0 \%$ & $0 \%$ & $2.1 \%$ \\
Triangular x Assimilated & $0 \%$ & $0 \%$ & $0 \%$ & $0 \%$ \\
Nodular x Truncated & $3.7 \%$ & $2.4 \%$ & $4.0 \%$ & $2.1 \%$ \\
Nodular x Triangular & $2.6 \%$ & $0 \%$ & $1.3 \%$ & $2.1 \%$ \\
Nodular x Nodular & $23.6 \%$ & $14.3 \%$ & $18.7 \%$ & $23.5 \%$ \\
Nodular x Assimilated & $2.6 \%$ & $2.4 \%$ & $0 \%$ & $6.5 \%$ \\
Assimilated x Truncated & $0 \%$ & $0 \%$ & $0 \%$ & $0 \%$ \\
Assimilated x Triangular & $0 \%$ & $0 \%$ & $0 \%$ & $0 \%$ \\
Assimilated x Nodular & $0 \%$ & $0 \%$ & $0 \%$ & $0 \%$ \\
Assimilated x Assimilated & $0 \%$ & $0 \%$ & $0 \%$ & $0 \%$ \\
\hline
\end{tabular}

data on South Brazilian population and Tuli et al., who studied the Indian population; in our study the triangular shape reached $23.3 \%$ of cases. Murlimanju et al. (2012) reported that the truncated, triangular and nodular shapes were equally prevalent in the South Indian population, distinct result to that reported by Lavanya Varma \& Sammer (2013) who found a higher prevalence for the nodular shape also in the South Indian population. The nodular shape was the most prevalent in the Turkish population (Sekerci \& Sisman), and also in the study of Shenoy et al. (2012). In our study the nodular shape was the second most prevalent, reaching $26.5 \%$ of cases. The assimilated shape was the least prevalent in our study and also in most studies reported in the literature, including Thai, Turkish and South Indian populations (Tuli et al.; Kositbowornchai et al.; Jansisyanont et al.; Murlimanju et al.; Shenoy et al.; Lavanya Varma \& Sammer; Sekerci \& Sisman) (Table I).

The lingula is one of the sexually dimorphic features which can be used efficiently in sexing of mandible (Nirmale et al.). Mulimanjur et al., report that found sexual dimorphism in South Indian mandibles, they claim that in males the triangular shape was more common and in females it was nodular. Nirmale et al., also claim that male mandibles show triangular shape commonly. Tuli et al. found the triangular shape as the most common in males and females. Kositbowornchai et al. and Jansisyanont et al. affirm that the truncated shape was the most common type in males and females. In our study we found that truncated shape was more prevalent in females and the triangular shape was more prevalent in males; the nodular and assimilated shapes were equally the least frequent in males and females. Furthermore, the triangular shape was more prevalent in black males than in black females, the truncated shape was more prevalent in white females than in white males and the nodular shape was more prevalent in white males than in white females. We agree with Tuli et al., Kositbowornchai et al. and Nirmale et al. when claim that the shape of the lingula shows differences between the sexes. Sekerci \& Sisman reported that for both males and females, the nodular and assimilated shapes were the most and the least prevalent types, respectively. These authors also reported that they found no different sex wise variation.

The same type of lingula bilaterally was the most common finding in most studies reported in the literature (Tuli et al.; Kositbowornchai et al.; Jansisyanont et al.; Lopes et al.; Murlimanju et al.; Tapas; Sekerci \& Sisman) and also in our study. The bilateral truncated shape was the most common finding in our study, as well as in surveys reported by Kositbowornchai $e t a l$. and Jansisyanont $e t$ al. in Thai population, however, it is noteworthy that the frequency of the same shape of lingula, bilaterally, varies according to the population studied. The bilateral triangular shape of the lingula was most common in Indian population (Tuli et al.) in South Indian population (Murlimanju et al.), in South Brazilian population (Lopes et al.) and also in the study of Nirmale et al. The bilateral nodular shape of the lingula was most common just for Turkish population (Sekerci \& Sisman). In our study there were no cases of bilateral assimilated shape of the lingula, however other studies have reported that this shape has been found between 1.5-14.6\% (Tuli et al.; Kositbowornchai et al.; Jansisyanont et al.; Lopes et al.; Murlimanju et al.; Nirmale et al.; Tapas; Sekerci \& Sisman). We also observed that the bilateral truncated shape was more frequent in females than in males, sex differences have also been reported by Tuli et al., Jansisyanont $e t$ al. and Murlimanju et al. The most common type of asymmetry 
in males, females and black individuals was "truncated $\mathrm{x}$ triangular"; in white individuals was "truncated x nodular".

We observed in this study that black and white individuals showed differences in the shape of the lingula. The truncated shape was the most common type for black males and the nodular shape was the most common type for white males. Already for black and white females the truncated shape was the most common type, followed by nodular and triangular shapes. Black males and black females had no case of assimilated shape, whereas white males and white females showed few cases of assimilated shape, being $2.9 \%$ and $3.8 \%$, respectively. The truncated shape was more prevalent in black individuals than in white individuals. The triangular shape was the only type that presented itself in similar proportions for black and white individuals. The nodular shape was more frequent in white individuals than in black individuals. We have not found the assimilated shape for black individuals, and for white individuals this shape was found in only $3.1 \%$. The literature reports important racial differences in studies with mandibles (Alves \& Deana, 2014), however we did not find any other study correlating race and shape of lingula.
Based on our results we can affirm that the truncated shape is the most common type, followed by nodular and triangular shapes; the assimilated shape was equally the least common type in males and females. In males and females, black and white individuals the same shape bilaterally was predominant. We observed racial differences, being the truncated shape the most common type in black individuals and the nodular shape in white individuals. Sex differences were found in truncated shape, which was more prevalent in women. Black individuals showed no case of assimilated shape. The shape of the lingula showed no side preference. Our findings facilitate the planning of oral and maxillofacial surgical procedures that involve the lingula and/or the inferior alveolar neurovascular bundle, avoiding operative complications.

\section{ACKNOWLEDGEMENTS}

Department of Morphology and Genetics - UNIFESP, São Paulo, Brazil.

ALVES, N. \& DEANA, N. F. Análisis de la forma de la língula en mandíbulas maceradas de individuos brasileños. Int. J. Morphol., 34(1):42-48, 2016.

RESUMEN: La língula de la mandíbula es una proyección ósea que limita medialmente el foramen mandibular, región en la cual penetra el fascículo vásculonervioso. Es un importante punto de referencia en cirugías maxilofaciales, utilizado en cirugías y en el bloqueo del nervio alveolar inferior. El objetivo fue analizar los diferentes tipos de língula encontrados en mandíbulas de individuos brasileños, considerándose aspectos como sexo y raza. Fueron utilizadas 132 mandíbulas maceradas de individuos brasileños adultos de ambos sexos, leucodermas y melanodermas. Se clasificó la língula en cuatro tipos: triangular, truncada, nodular y asimilada. Para el análisis estadístico se utilizó el Chi-cuadrado y la prueba exacta de Fisher. La forma truncada fue la más frecuente (49\%), seguida de la nodular $(26,5 \%)$ y triangular $(23,3 \%)$. La forma asimilada fue menos prevalente, con el 1,2\%. Cada tipo de língula fue más común bilateral. Considerando el color de piel se observó que la forma truncada fue más prevalente en melanodermas que en leucodermas y la forma nodular fue más prevalente en leucodermas que en melanodermas. No se encontró la forma asimilada en individuos melanodermas. Considerando el sexo, se observó que la forma truncada fue más frecuente en mujeres que en hombres y la forma triangular más frecuente en hombres que en mujeres. La forma de la língula mostró no tener preferencia por lado. Nuestros hallazgos facilitan la planificación de los procedimientos quirúrgicos orales y maxilofaciales que implican la língula y/o el paquete neurovascular alveolar inferior, evitando complicaciones operatorias.

PALABRAS CLAVE: Anatomía; Língula; Mandíbula; Nervio alveolar inferior.

\section{REFERENCES}

Alves, N. \& Cândido, P. Anatomia para o curso de odontologia geral e específica. $3^{\mathrm{a}}$ ed. Gen-Santos, São Paulo, 2012.

Alves, N. \& Deana, N. F. Morphometric study of mandibular foramen in macerated skulls to contribute to the development of sagittal split ramus osteotomy (SSRO) technique. Surg. Radiol. Anat., 36(9):839-45, 2014.
Alves, N. \& Deana, N. F. Morphological study of the lingula in adult human mandibles of Brazilians individuals and clinical implications. Biomed Res. Int., 2015:873751, 2015.

Dal Pont, G. Retromolar osteotomy for the correction of prognathism. J. Oral Surg. Anesth. Hosp. Dent. Serv., 19:427, 1961. 
Jansisyanont, P.; Apinhasmit, W. \& Chompoopong, S. Shape, height, and location of the lingula for sagittal ramus osteotomy in Thais. Clin. Anat., 22(7):787-93, 2009.

Keros, J.; Kobler, P.; Baucic, I. \& Cabov, T. Foramen mandibulae as an indicator of successful conduction anesthesia. Coll. Antropol., 25(1):327-31, 2001.

Kositbowornchai, S.; Siritapetawee, M.; Damrongrungruang, T.; Khongkankong, W.; Chatrchaiwiwatana, S.; Khamanarong, K. \& Chanthaooplee, T. Shape of the lingula and its localization by panoramic radiograph versus dry mandibular measurement. Surg. Radiol. Anat., 29(8):689-94, 2007.

Lavanya Varma, C. \& Sameer, P. A. Morphological variations of lingula in South Indian mandibles. Res. Rev. J. Med. Health Sci., 2(1):31-4, 2013.

Lopes, P. T. C.; Pereira, G. A. M. \& Santos, A. M. P. V. Morphological analysis of the lingula in dry mandibles of individuals in Southern Brazil. J. Morphol. Sci., 27(3-4):1368,2010

Murlimanju, B. V.; Prabhu, L. V.; Pai, M. M.; Paul, M. T.; Saralaya, V. V. \& Kumar, C. G. Morphological study of lingula of the mandibles in South Indian population. Morphologie, 96(312):16-20, 2012.

Nicholson, M. L. A study of the position of the mandibular foramen in the adult human mandible. Anat. Rec., 212(1):110-2, 1985.

Nirmale, V. K.; Mane, U. W.; Sukre, S. B. \& Diwan, C. V. Morphological features of human mandible. Int. J. Recent Trends Sci. Technol., 3(2):38-43, 2012.

Salgado, A. G.; Inzunza, H. O.; Cantín, M.; Fuentes, R.; Inostroza, V.; Errázuriz, M. J. \& Pavez, C. Evaluation of mandibular anatomy related to sagittal split ramus osteotomy. Int. J. Morphol., 30(1):30-9, 2012.

Sekerci, A. E. \& Sisman, Y. Cone-beam computed tomography analysis of the shape, height, and location of the mandibular lingula. Surg. Radiol. Anat., 36(2):155-62, 2014.

Shenoy, V.; Vijayalakshmi, S. \& Saraswathi, P. Osteometric analysis of mandibular foramen in dry human mandibles. J. Clin. Diagn. Res., 6(4):557-60, 2012.

Tapas, S. Variations in the morphological appearance of lingula in dry adult human mandibles. Int. J. Cur. Res. Rev., 5(24):41-5, 2013.

Tuli, A.; Choudhry, R.; Choudhry, S.; Raheja, S. \& Agarwal, S. Variation in shape of the lingula in the adult human mandible. J. Anat., 197(Pt. 2):313-7, 2000.
Yoshida, T.; Nagamine, T.; Kobayashi, T.; Michimi, N.; Nakajima, T.; Sasakura, H. \& Hanada, K. Impairment of the inferior alveolar nerve after sagittal split osteotomy. $J$. Craniomaxillofac. Surg., 17(6):271-7, 1989.

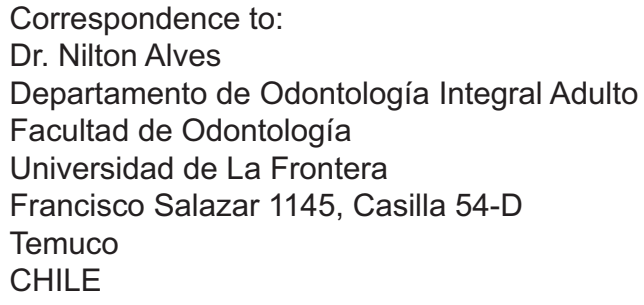

Email: niltonnalves@yahoo.com.br

Received: 28-04-2015

Accepted: 06-11-2015 